\title{
SEARCH AND INVESTIGATION OF COLD EMISSION IN THE SOLAR CORONA OF AUGUST 11, 1999
}

\author{
G. Yakunina, O. Smirnova, A. Delone, A. Gorshkov, G. Porfir'eva \\ Sternberg Astronomical Institute, Moscow, 119899, Russia
}

(Received July 22, 2002; received in final form September 22, 2002)

\begin{abstract}
The cold coronal emission was revealed during the interferometric observations of the solar eclipse. The emission weak lines of $\mathrm{H}_{\alpha} 6563 \AA$ and $\mathrm{K}$ CaII $3933 \AA$ and the coronal line Fe XIV $5303 \AA$ were used. The cold region was inhomogeneous by its characteristics. Temperature and motions were determined in it.
\end{abstract}

Key words: Sun, corona, plasma motions.

PACS number(s): 96.60.Pb

The solar corona is known to be a hot plasma phenomenon with the electron temperature $T \geq 1 \times 10^{6} \mathrm{~K}$ and low density $n_{e} \leq 10^{-8} \mathrm{~cm}^{-3}$. It is observed in lines of high ionized elements in wide spectral region. The strongest coronal lines in the visible spectrum are the lines of Fe X $(\lambda 6374 \AA)$, Fe XIV $(\lambda 5303 \AA)$, and Ca XV $(\lambda 6374 \AA)$ with $T \cong(1-3) \times 10^{6} \mathrm{~K}$. However, since 1868 , a faint $\mathrm{H}_{\alpha}$-emission in the corona, having $T \sim\left(10^{4}-10^{5}\right)$ $K$, has been observed more than once during and out of the solar eclipses from the Earth. A review of the results of the cold corona investigations is given in [1]. Successful observations of the cold corona were also obtained in [24]. Modern X-ray and EUV space observations also show that the corona is very dynamic and inhomogeneous by its structure [5].

The aim of this investigation was to search the cold coronal emission during the solar eclipse on August 11,
1999 and to detect its temperature. The observations were carried out in Bulgaria on the Black seashore. A horizontal solar instrument, consisting of two coelostat mirrors, feeding two parallel tubes with identical optical and signal registration systems, was used to photograph the solar corona in three wavelengths. This installation, assembled in Sternberg Institute, was exploited for the first time during the observations in August of 1999. The Fabry-Perot interferometers for the $\mathrm{H}_{\alpha}, \mathrm{K}$ CaII and $\mathrm{Fe}$ XIV lines together with the corresponding interference filters were employed, two of them were replaced consequently in one tube. The interference filters with the full widths of $15 \AA$ for the Fe XIV and $\mathrm{H}_{\alpha}$ lines and $40 \AA$ for the $\mathrm{K}$ CaII line were used as the premonochromators. The observations, instrument and the method of the treatment are described in more details in [6].
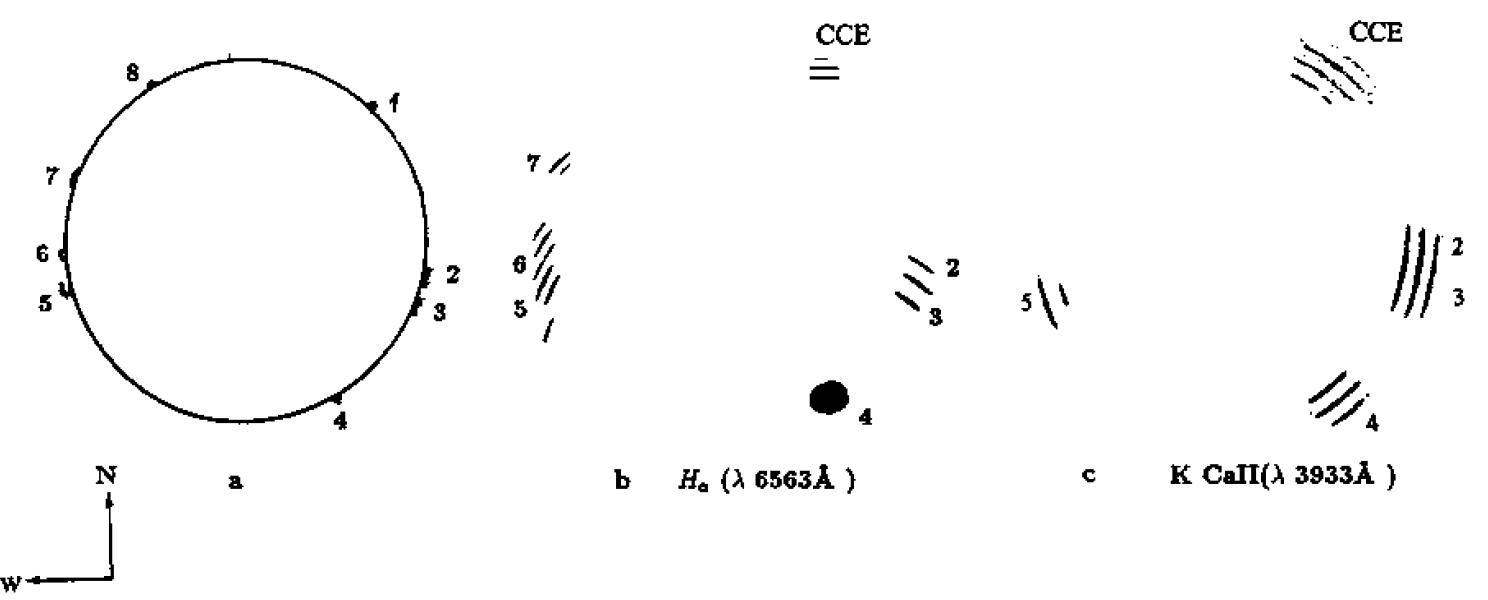

b $H_{0}(\lambda 6563 \AA)$

c K $\operatorname{CaII}(A 3933 \AA)$

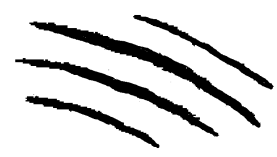

d

Fig. 1. Schematic drawing of the location of the prominences (a) and $\mathrm{H}_{\alpha}, 10 \mathrm{~s}$ (b), and K CaII, $10 \mathrm{~s}$ (c, d) interferograms of the solar corona during the eclipse on 11 August, 1999. CCE is the cold coronal emission. The north is on the top and the west is on the left. 
The negatives were digitized and the conversion into the intensities was performed by using the characteristic curve approximated by a ratio of polynomials. In Figure 1 a schematic drawing of the locations of the prominences, seen in $\mathrm{H}_{\alpha}$ (according to data from Internet and observations on Crimea observatory on August 11), and interferograms in two $\lambda \lambda$ are shown. For the convenience the prominences were numbered. The numbers on the interferograms (Fig. 1 b, c) indicate approximately the position angles of the corresponding prominences. The differences between the locations (or intensities), seen in $\mathrm{H}_{\alpha}$ and $\mathrm{K} \mathrm{Ca}$ II, are possibly caused by differences of the time moments during the full eclipse phase. K Ca II interferogram was photographed in the first half of the totality and $\mathrm{H}_{\alpha}$ and green ones were photographed during the second half of the eclipse, when the west prominences became visible.

The emission on the $\mathrm{H}_{\alpha}$ and $\mathrm{K}$ Ca II interferograms has been revealed to be more intense in the places, where $\mathrm{H}_{\alpha}$-prominences were situated, but there were the interference rings in the site CCE (Fig. 1 b, c), where no prominence was observed. We consider these regions as those of the so-called "weak $\mathrm{H}_{\alpha}$-emission" and named them "CCE" (cold coronal emission). The $\mathrm{H}_{\alpha}$ and $\mathrm{K} \mathrm{Ca}$ II CCE-s coinside by their locations. We believe that these CCE-s can not be artificial images caused by some light scattering in the instrument, because the $\mathrm{H}_{\alpha}$ and $\mathrm{K}$ Ca II interferograms were taken independently on the different optical tubes and with different inclinations of the corresponding interference filters and Fabry-Perot interferometers. In Figure $1 \mathrm{~d}$ the $\mathrm{K}$ Ca II CCE is shown in a larger scale. A fine structure is distinctly seen.

The centers of the $H_{\alpha}$ and K Ca II interferograms were found to be correspondingly near the prominence 4 (Fig. $1 \mathrm{~b}$ ) and in the centre of the solar disk (Fig. 1 c), that is why the $\mathrm{H}_{\alpha}$ and $\mathrm{K}$ Ca II interference rings are turned relatively to each other in the CCE region. But we believe that we see the same coronal bulk in the $\mathrm{H}_{\alpha}$ and K Ca II lines and consider the mean characteristics over this volume. Using a special program of treatment, about 16 radial cross-cuts from the centres of the interferogram pictures throuth the more intense $\mathrm{K}$ Ca II details and at the same $\mathrm{H}_{\alpha}$ sites were made and 62 and 69 line profiles of different coronal features were obtained correspondingly in $\mathrm{H}_{\alpha}$ and K Ca II. The Doppler widths $\Delta \lambda_{\mathrm{D}}{ }^{\text {obs }}$ of the line profiles and shifts with respect to the average ring positions were measured, which allowed to investigate the motions in the coronal plasma. The observed widths $\Delta \lambda_{\mathrm{D}}{ }^{\text {obs }}$ were corrected for the instrumental broadening. The corrected Doppler widths $\Delta \lambda_{\mathrm{D}}$ of an optically thin line is related to the temperature $T$ and turbulent velocity $\xi$ by the equation

$$
\frac{\Delta \lambda_{\mathrm{D}}}{\lambda} c=\sqrt{\frac{2 k T_{i}}{M_{i}}+\xi^{2}},
$$

where $M_{i}$ is the mass of the ion producing the line emission, $k$ is the Boltzmann constant, $c$ is the speed of the light, and $\lambda$ is the standard wavelength of the emission line.
The turbulent velocity $\xi$ is the excess amount of the observed line width over the thermal contribution $v_{\text {th }}=$ $\sqrt{\frac{2 k T_{i}}{M_{i}}}$. The bigger $M_{i}$ is the smaller the thermal contribution is. The relations between $\Delta \lambda_{\mathrm{D}}$ and $\xi$ were calculated for the $\mathrm{H}_{\alpha}$ and $\mathrm{K}$ Ca II lines. A set of the temperatures from $10^{4} \mathrm{~K}$ to $2 \times 10^{5} \mathrm{~K}$ was used. The Doppler width $\Delta \lambda_{\mathrm{D}}$ against the $\xi$ for the two lines considered is plotted in Figure $2 \mathrm{a}$, b. The various temperature curves almost do not differ for the Ca II line, except the small $\xi$ range, but they differ noticeably for the $\mathrm{H}_{\alpha}$-line. We suppose that we observed the same coronal bulk both in the $\mathrm{H}_{\alpha}$ and $\mathrm{K}$ CaII lines and that $\mathrm{H}_{\alpha}$ and $\mathrm{K} \mathrm{CaII}$ corona had almost equal mean $T$ and $\xi$, implying the mean values over the CCE-volume.
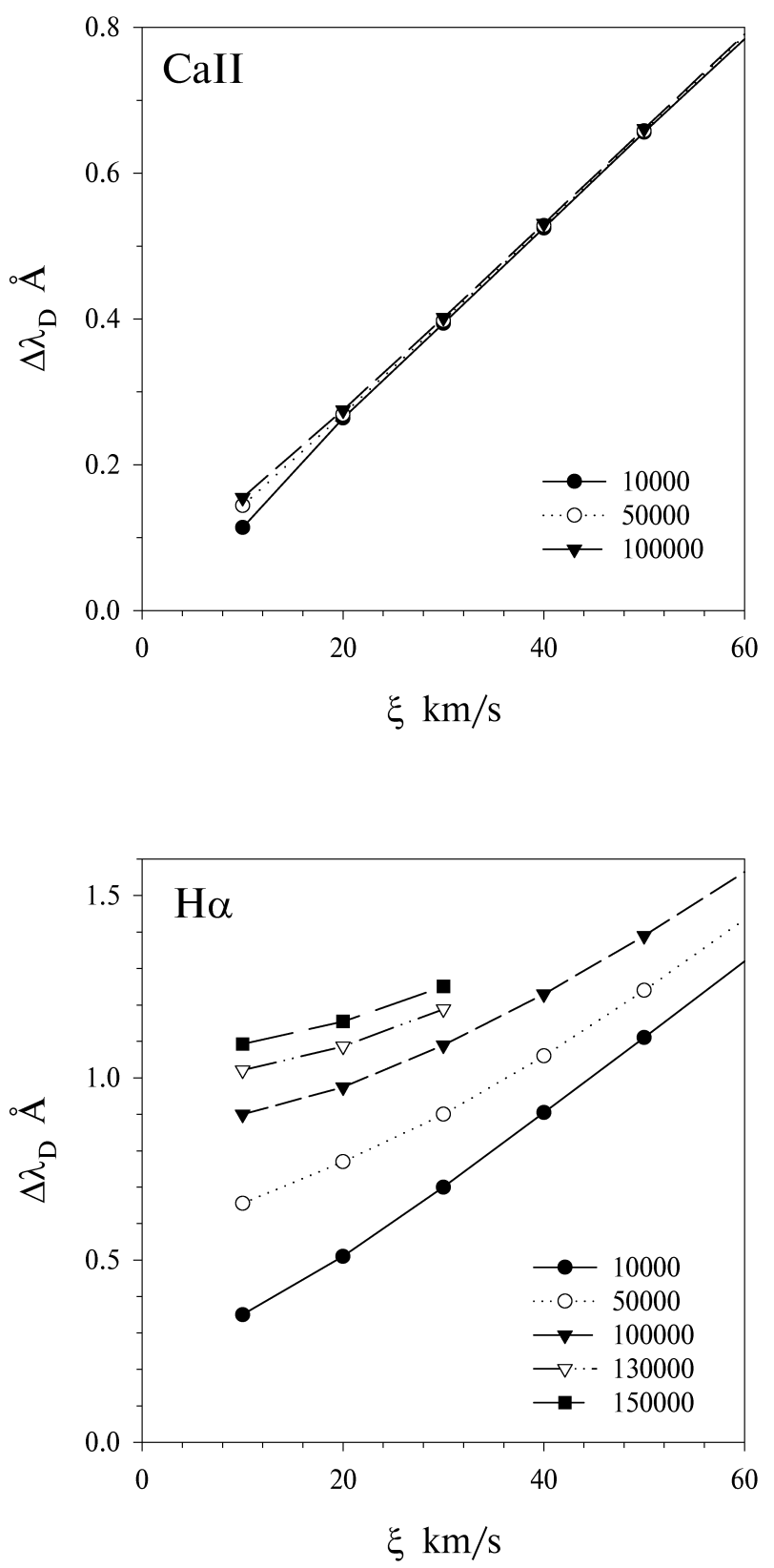

Fig. 2. The Doppler width $\Delta \lambda_{\mathrm{D}}$ against the turbulent velocity $\xi$ for the $\mathrm{K}$ CaII (a) and $\mathrm{H}_{\alpha}$ (b) lines for different temperatures given in $\mathrm{K}$. 
For the $\mathrm{K}$ CaII line the Doppler widths $\Delta \lambda_{\mathrm{D}}$ change from $0.23 \AA$ to $0.46 \AA$ with the $\overline{\Delta \lambda_{\mathrm{D}}}=0.30 \AA$, yielding the velocity $\xi$ changing in the range from $17 \mathrm{~km} \cdot \mathrm{s}^{-1}$ to $28 \mathrm{~km} \cdot \mathrm{s}^{-1}$ and the $\bar{\xi}=20 \mathrm{~km} \cdot \mathrm{s}^{-1}$ accordingly to the relation in Figure $2 \mathrm{a}$. For the $\mathrm{H}_{\alpha}$-line $0.75 \AA \leq$ $\Delta \lambda_{\mathrm{D}} \leq 1.30 \AA$ with the $\overline{\Delta \lambda_{\mathrm{D}}}=1.07 \AA$. Having the range of the change for $\Delta \lambda_{\mathrm{D}}\left(\mathrm{H}_{\alpha}\right)$ and $\xi(\mathrm{KCaII})$, we evaluated the temperature in the cold corona region using the relations shown in Figure $2 \mathrm{~b}$. The temperature was found to change from $5 \cdot 10^{4} \mathrm{~K}$ to $1.3 \cdot 10^{5} \mathrm{~K}$. The lineof-sight velocities in the CCE-bulk were from $20 \mathrm{~km} \cdot \mathrm{s}^{-1}$ to $150 \mathrm{~km} \cdot \mathrm{s}^{-1}$. In the $\mathrm{H}_{\alpha}$-line the $\xi=100 \mathrm{~km} \cdot \mathrm{s}^{-1}$ and $\xi=135 \mathrm{~km} \cdot \mathrm{s}^{-1}$ were more probable, and in the $\mathrm{K}$ CaII line the $\xi=45 \mathrm{~km} \cdot \mathrm{s}^{-1}$ did. However, the CaII value might be underestimated because of the instrumental limitation.

We conclude that the investigated cold coronal region was dynamic and not homogeneous by its temperature and velocities. The dimension of the CCE was determined to be of $3.5^{\prime} \times 4^{\prime}$. The observation from the Earth are confirmed with the space investigations. The SUMER Spectrometer on SOHO has been used to observe the lines of the hydrogen Lyman series [7]. The line profiles were obtained near the limb from about $(-10)^{\prime \prime}$ to $70^{\prime \prime}$. The temperature ranged between $1 \cdot 10^{5} \mathrm{~K}$ to $2 \cdot 10^{5} \mathrm{~K}$. The line broadening appears to be very large for the thermal contribution. With an assumed turbulent speed of $30 \mathrm{~km} \cdot \mathrm{s}^{-1}[8]$ the $T$ has been calculated to be $1.2 \cdot 10^{5} \mathrm{~K}$. Comparing our results with the results in [7] we can conclude that they agree sufficiently well. The cold corona is characterized by the temperatures which are one-two orders lower than the "usual" corona in quiet regions, but by its turbulent and line-of-sight velocities it is likely to be more dynamic than the quiet corona.
[1] V. N. Dermendjiev, Theoretical and Observational Problems Related to Solar Eclipses, 131 (Kluwer Academic Publishers, Netherlands, 1997).

[2] N. Gopalswamy, S. M. White, M. R. Kundu, Astrophys. J. 379, 366 (1991).

[3] A. B. Delone, M. I. Divlekeev, O. B. Smirnova, G. V. Yakunina, Astron. Lett. 25, 46 (1999).

[4] P. I. Duchlev, Sol. Phys. 199, 107 (2001).

[5] P. Brekke, ASP Conf. Ser. 155, 150 (1998).

[6] A. Delone, M. Divlekeev, A. Gorshkov, G. Porfir'eva,
O. Smirnova, G. Yakunina, T. Birulia, E. Sukhanov, V. Abramenko, Proc. Inter. Conf. "First Results of 1999 Total Eclipse Observations" 2000, edited by Acad. D. N. Mishev, Prof. K. J. H. Phillips, (Varna, Bulgaria, September 11-15, 2000), p. 235.

[7] E. Marsch, C.-Y. Tu, K. Wilhelm, Astron. Astrophys. 359, 381 (2000).

[8] E. Marsch, C.-Y. Tu, P. Heinzel, K. Wilhelm, W. Curdt, Astron. Astrophys. 347, 676 (1999).

\title{
ПОШУКИ ТА ДОСЛІДЖЕННЯ ХОЛОДНОї ЕМІСІї В СОНЯЧНІЙ КОРОНІ 11 СЕРПНЯ 1999 РОКУ
}

\author{
Г. Якуніна, О. Смирнова, А. Делоне, А. Горшков, Г. Порфир'єва \\ Астрономічний інститут IIIтернберга, Москва, 119899, Росія
}

\begin{abstract}
Виявлено холодну корональну емісію під час інтерферометричних спостережень сонячного затемнення. Використано слабкі емісійні лінії $\mathrm{H}_{\alpha} 6563 \AA$ i K CaII $3933 \AA$ та корональну лінію Fe XIX $5303 \AA$. Холодна ділянка була неоднорідною за своїми характеристиками. Визначено температуру й швидкості рухів у ній.
\end{abstract}

